\title{
Revenue Sharing Contract in a Multi-Echelon Supply Chain with Fuzzy Demand and Asymmetric Information
}

\author{
Shengju Sang* \\ Department of Economics and Management, Heze University, \\ No.2269 University Road, Heze, Shandong, 274015, China ${ }^{\dagger}$ \\ E-mail: sangshengju@163.com
}

Received 5 March 2015

Accepted 27 June 2016

\begin{abstract}
In this paper, we consider the revenue sharing contract between supply chain actors in a multi-echelon supply chain, where the demand of the customers and retail price are fuzzy variables. The centralized decision making system and a coordinating contract, namely, the revenue sharing contract with fuzzy demand and asymmetric information are proposed. To derive the optimal solutions, the fuzzy set theory is applied for solving these models. Finally, the optimal results of proposed models are illustrated with three numerical experiments. The effects of the fuzziness of retail price and demand, different contract parameters on the optimal strategies for supply chain actors are also analyzed.
\end{abstract}

Keywords: Revenue sharing contract, fuzzy variables, asymmetric information, multi-echelon supply chain

\section{Introduction}

Over the past ten years, revenue sharing (RS) contract has attracted a lot of attention from both scholars and practitioners, and has achieved much success in film studios and video rental industry. In the revenue sharing contract, the sum of the expected profits of all supply chain actors is the same as the maximum expected profit derived in the centralized decision making system.

An adequate number of papers discussed the RS contract in the two-echelon supply chains under a linear or random demand setting. Cachon and Lariviere ${ }^{1}$ studied the strengths and limitations of the RS contract. Hou et $a l .{ }^{2}$ considered a RS and bargaining model in which the profit of the retail was sensitive to the lead time of the manufacturer. Giannoccaro and Pontrandolfo ${ }^{3}$ developed an agent-based systems model to study the negotiation problem of the RS contract. Chen et al. ${ }^{4}$ investigated the problem of channel coordination by using RS contract, where the demands for customers are non-linear functions of the retail price and the size of self-space. Sheu $u^{5}$ proposed a RS contract to coordinate a supplierretailer distribution channel with three types of price promotion patterns to customers. Kunter ${ }^{6}$ investigated how to coordinate a manufacturer-retailer channel using cost and RS contact. Chen and $\mathrm{Cheng}^{7}$ developed the price-dependent and price-independent RS contracts models in a vendor-buyer channel. They found that in price-independent RS contracts the supply chain actors can obtain higher profits than those price-dependent RS contracts. Sarathi et al. ${ }^{8}$ used a mixed RS and quantity discounts contract to coordinate a two-echelon supply chain. Govindan and Popiuc ${ }^{9}$ developed a RS contract aimed at coordinating a reverse supply chain in the personal computers industry. Recently, socially responsible of the supply chain actors was taken into

\footnotetext{
* Department of Economics and Management, Heze University, Heze, Shandong, China

${ }^{\dagger}$ China, Heze University, E-mail: sangshengju@163.com
} 
account in the RS contract. Panda ${ }^{10}$ used the RS contract to coordinate a socially responsible two stage supply chain with considering two cases, corporate social responsible retailer and corporate social responsibility manufacturer in a linear demand. Hsueh ${ }^{11}$ also developed a RS contract embedding corporate social responsibility for coordinating a two-echelon supply chain with random demand. Linh and Hong ${ }^{12}$ discussed how to set the wholesale and RS ratio in a two-period model by using the RS contract. Palsule-Desai ${ }^{13}$ also studied the coordination problem of the supply chain in a two-period model via revenue-dependent RS contract. In addition, some studies have been done on analyzing competition problems of the supply chain actors in the RS contract. Yao et al. ${ }^{14}$ used the RS contract to coordinate the supply chain with two competing retailers and one manufacturer. Pan et al. ${ }^{15}$ compared RS contract to wholesale price policy with two manufacturers and one retailer, two retailers and one manufacturer under different channel power structures. Ouardighi and $\mathrm{Kim}^{16}$ developed a differential game model with wholesale price and RS contracts between two manufacturers and one supplier. Krishnan and Winter ${ }^{17}$ studied the coordinating role of RS contract with two competing retailers. Zhang et al. ${ }^{18}$ studied the RS contract in a supply chain consisting of two competing retailers with demand disruption. Recently, Chakraborty et al. ${ }^{19}$ studied the RS mechanisms with two competing manufacturers and one retailer under a linear stochastic demand. Zhang et al. ${ }^{20}$ proposed a RS and cooperative investment contract for deteriorating items to coordinate a supply chain. Arani et al..$^{21}$ proposed a novel mixed revenue-sharing option contract for coordinating a retailer-manufacturer supply chain.

Some literature focused on the RS contract in a multiechelon supply chain. For example, Giannoccaro and Pontrandolfo $^{22}$ studied the RS contract in a three-echelon supply chain. Rhee et al. ${ }^{23,24}$ proposed a spanning RS contract to coordinate a multi-stage supply chain with random demand. Jiang et al. ${ }^{25}$ developed a spanning RS contract comprising two competing manufacturers, one distributor and one retailer with a linear demand function in a three-echelon supply chain. Feng et al. ${ }^{26}$ studied the RS contract with more than one actor at some echelons in a multi-echelon supply chain. Only a few of articles addressed the RS contract in a fuzzy environment. Wang et al. ${ }^{27}$ studied the RS contract with two fuzzy demand forms in a two-stage supply chain. Sang ${ }^{28}$ developed a RS contract to coordinate a supply chain with one supplier and multiple retailers in a fuzzy demand environment.

All studies mentioned above mainly discussed the RS contract under a linear or probabilistic market demand and known retail price. However, in today's highly competitive market, shorter and shorter product life cycles make the useful statistical data less and less available. Thus, in recent years, fuzzy set theory has been adopted by more and more scholars to solve fuzzy supply chain problems. Zhou et al. ${ }^{29}$ studied the price decision problem between a manufacturer and one retailer, where the demand and the manufacturing cost were considered as fuzzy variables. Sang ${ }^{30}$ extended this work to a fuzzy supply chain with two competitive retailers and one manufacturer, where two retailers pursued the Cournot and Stackelberg games. Dang and Hong ${ }^{31}$ developed a Cournot game in a fuzzy supply chain, where the demand and costs were treaded as triangular fuzzy numbers. Dang et $a l .{ }^{32}$ further studied this fuzzy Cournot game with multiple firms. Zhao et al. ${ }^{33}$ considered the pricing decisions in a two-echelon supply chain, where one manufacturer sold his substitutable products to two competing retailers. Zhao et al. ${ }^{34}$ studied the service and price decisions with two competing manufacturers and one retailer in a fuzzy environment. Zhao and $\mathrm{Wang}^{35}$ also studied the pricing and service decisions with one manufacturer and two retailers in fuzzy linear demand

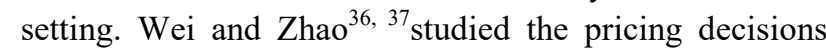
problem of retail competition and reverse channel decisions in a fuzzy decision environment. Khamseh et $a l .^{38}$ studied the pricing policies of a fuzzy two-echelon supply chain with two competing manufacturers in both cooperation and non-cooperation situations. Sang ${ }^{39}$ studied the pricing decisions of a fuzzy two-echelon supply chain with two competing manufacturers in which the attitudes of the members to the risk were considered. Recently, some researchers developed the fuzzy newsboy model in a supply chain. Xu and Zhai ${ }^{40,41}$ developed a fuzzy newsboy model in a two-stage supply chain, in which demands were considered as triangular fuzzy variables. $\mathrm{Yu}$ and $\mathrm{Jin}^{42}$ developed a return policy to coordinate the supply chain actors in which the demand and retail price were assumed to be fuzzy variables. Yu et al. ${ }^{43}$ also studied the fuzzy newsboy model in a fuzzy price-dependent demand setting. In addiction, Chang and $\mathrm{Yeh}^{44}$ explored a return policy with fuzzy demand in a two-stage supply chain, where unsatisfactory products were returned to the manufacturer. Zhang et al. ${ }^{45}$ studied 
the buyback contract for coordinating a fuzzy two-stage supply chain, where demand was assumed to be a fuzzy random variable.

As far as we know, there are no studies on the RS contract in a fuzzy multi-stage supply chain. However, in real life, the rapid change of the product life cycle makes the parameters of the supply chain models more and more uncertain. These uncertainties may be the market demand, operations costs of the product, etc. In addition, a supply chain is usually made up more than two stages. Then, a natural question is how to design a coordination mechanism in a multi-stage supply chain. Therefore, in this article, we concentrate on the RS contract in a multistage supply chain, in which the demand, retail price and operational costs are all fuzzy. Furthermore, we discuss the impact of fuzziness for demand and retail price on the RS policy.

The contributions of this article are as follows. Firstly, we extend the works of $\mathrm{Sang}^{28,30}$ to a multiple echelon supply chain in a fuzzy demand environment. Secondly, we study the RS contract in an asymmetric information environment in which both the market demand and the retail price are considered as fuzzy variables. Thirdly, we analyze the impacts of the fuzziness of retail price and market demand on the optimal policies in the RS contract.

The reminder of paper is as follows. Some definitions and propositions about fuzzy set theory are introduced in Section 2. Section 3 describes the problem. In Section 4, we develop two fuzzy supply chain models with asymmetric information. In Section 5, three numerical examples are given to illustrate the solutions for proposed models. Section 6 summarizes the work and indicates future work directions.

\section{Preliminaries}

Definition 1. The fuzzy set $\tilde{A}=(a, b, c)$ is said to be a triangular fuzzy variable if it has a following membership function

$$
\mu_{\tilde{A}}(x)=\left\{\begin{array}{cc}
\frac{x-a}{b-a}, & a \leq x \leq b, \\
\frac{c-x}{c-b}, & b \leq x \leq c, \\
0, & x \notin(b, c) .
\end{array}\right.
$$

where $a, b$ and $c$ are real numbers with $a<b<c$. For $x \in[a, b], \tilde{A}_{L}(x)=\frac{x-a}{b-a}$ is continuous and strictly increasing with respect to $x$. For $x \in(b, c], \tilde{A}_{R}(x)=$ $\frac{c-x}{c-b}$ is continuous and strictly decreasing with respect to $x$.

Definition 2. Given $\alpha \in[0,1]$, the set $\tilde{A}(\alpha)=\left\{x \mid \mu_{\tilde{A}}(x) \geq\right.$ $\alpha\}$ is said to be the $\alpha$ cut set of $\tilde{A}$ and is denoted by the $\operatorname{interval}\left[\tilde{A}_{L}^{-1}(\alpha), \tilde{A}_{R}^{-1}(\alpha)\right]$, with

$$
\begin{aligned}
& \tilde{A}_{L}^{-1}(\alpha)=\inf \left\{x \in R: \mu_{\tilde{A}(x)} \geq \alpha\right\}, \\
& \tilde{A}_{R}^{-1}(\alpha)=\sup \left\{x \in R: \mu_{\tilde{A}(x)} \geq \alpha\right\} .
\end{aligned}
$$

where $\tilde{A}_{L}^{-1}(\alpha)$ and $\tilde{A}_{R}^{-1}(\alpha)$ are the left and right cut sets of $\tilde{A}(\alpha)$.

Example 1. Given $\alpha \in[0,1]$, the $\alpha$ cut set of $\tilde{A}=(a, b, c)$ can be given as

$$
\tilde{A}_{L}^{-1}(\alpha)=a+(b-a) \alpha, \tilde{A}_{R}^{-1}(\alpha)=c+(b-c) \alpha .
$$

Proposition 1. Given $\alpha \in[0,1]$, let $\tilde{A}$ be a positive triangular fuzzy variable with $\alpha$ cut set $\left[\tilde{A}_{L}^{-1}(\alpha), \tilde{A}_{R}^{-1}(\alpha)\right]$, then

$$
k \tilde{A}(\alpha)= \begin{cases}{\left[k \tilde{A}_{L}^{-1}(\alpha), k \tilde{A}_{R}^{-1}(\alpha)\right],} & k \in R^{+}, \\ {\left[k \tilde{A}_{R}^{-1}(\alpha), k \tilde{A}_{L}^{-1}(\alpha)\right],} & k \in R^{-} .\end{cases}
$$

Proposition 2. Given $\alpha \in[0,1]$, let $\tilde{B}$ and $\tilde{C}$ be two positive triangular fuzzy numbers with $\alpha$ cut set $\left[\tilde{B}_{L}^{-1}(\alpha), \tilde{B}_{R}^{-1}(\alpha)\right]$ and $\left[\tilde{C}_{L}^{-1}(\alpha), \tilde{C}_{R}^{-1}(\alpha)\right]$, respectively. Then we have

$$
\begin{aligned}
& \text { (1) } \tilde{B}(\alpha)+\tilde{C}(\alpha)=\left[\tilde{B}_{L}^{-1}(\alpha)+\tilde{C}_{L}^{-1}(\alpha), \tilde{B}_{R}^{-1}(\alpha)+\tilde{C}_{R}^{-1}(\alpha)\right], \\
& \text { (2) } \tilde{B}(\alpha)-\tilde{C}(\alpha)=\left[\tilde{B}_{L}^{-1}(\alpha)-\tilde{C}_{R}^{-1}(\alpha), \tilde{B}_{R}^{-1}(\alpha)-\tilde{C}_{L}^{-1}(\alpha)\right], \\
& \text { (3) }(\tilde{A} \tilde{B})_{L}^{-1}(\alpha)=\tilde{A}_{L}^{-1}(\alpha) \tilde{B}_{L}^{-1}(\alpha), \\
& \text { (4) }(\tilde{A} \tilde{B})_{R}^{-1}(\alpha)=\tilde{A}_{R}^{-1}(\alpha) \tilde{B}_{R}^{-1}(\alpha) .
\end{aligned}
$$

Proposition 3 (Liu and $\mathrm{Liu}^{46}$ ). Let $\tilde{A}$ be a positive triangular variable with $\alpha$ cut $\operatorname{set}\left[\tilde{A}_{L}^{-1}(\alpha), \tilde{A}_{R}^{-1}(\alpha)\right]$. If the expected value of $\tilde{A}$ exists, then 


$$
E[\tilde{A}]=\frac{1}{2} \int_{0}^{1}\left[\tilde{A}_{L}^{-1}(\alpha)+\tilde{A}_{R}^{-1}(\alpha)\right] \mathrm{d} \alpha .
$$

Proposition 4 ( $\mathrm{Liu}$ and $\mathrm{Liu}^{46}$ ). Let $\tilde{A}$ and $\tilde{B}$ be two independent positive triangular fuzzy variables. If their expected values exist, then for any numbers $m$ and $n$

$$
E[m \tilde{A}+n \tilde{B}]=m E[\tilde{A}]+n E[\tilde{B}] .
$$

\section{Problem Descriptions}

Consider a linear supply chain structure with only one actor at each of the $n \geq 2$ echelons in a single period setting. Denote the supply chain actor 1 as the most downstream company and actor $n$ as the most upstream company. The supply chain actor 1 sells the product to customer in a high uncertain demand setting. The uncertain demand faced by the supply chain actor 1 is supposed to be a triangular fuzzy number $\tilde{D}=\left(d_{1}, d_{2}, d_{3}\right)$, where $0<d_{1}<d_{2}<d_{3} . d_{2}$ is the most possible value of the demand $\tilde{D}$, this means that the demand is about $d_{2}$. $d_{1}$ and $d_{3}$ respectively denote the minimum and maximum values of the demand. The fuzzy demand has the following membership function $\mu_{\tilde{D}}(x)$

$$
\mu_{\tilde{D}}(x)=\left\{\begin{array}{cc}
L(x), & x \in\left[d_{1}, d_{2}\right], \\
R(x), & x \in\left(d_{2}, d_{3}\right], \\
0, & x \notin\left(d_{1}, d_{3}\right) .
\end{array}\right.
$$

For convenience, the left and right spread functions of the fuzzy demand $\tilde{D}$ are denoted by $L(x)$ and $R(x)$.

In the asymmetric information environment, the supply chain actor 1 does not share his complete information of retail price with other actors. Therefore, the retail price will be estimated by the decision makers. Assuming the fuzzy retail price $\tilde{p}=\left(p-\Delta_{1}, p, p+\Delta_{2}\right)$ is considered as a positive triangular fuzzy variable, and denoted by a general membership function $\mu_{\tilde{p}}(x)$ :

$$
\mu_{\tilde{p}}(x)=\left\{\begin{array}{cc}
\tilde{p}_{L}(x), & x \in\left[p-\Delta_{1}, p\right], \\
\tilde{p}_{R}(x), & x \in\left(p, p+\Delta_{2}\right], \\
0, & i x \notin\left(p-\Delta_{1}, p+\Delta_{2}\right) .
\end{array}\right.
$$

The supply chain actor $i$ faces the wholesale price $w_{i+1}$ offered by actor $i+1$, and per unit fuzzy operational $\operatorname{cost} \tilde{c}_{i}=\left(c_{i 1}, c_{i 2}, c_{i 3}\right)$, and can set his selling price $w_{i}, i=2,3, \ldots, n$. For convenience of notation it is assumed that $w_{n+1}=0$. Thus, the supply chain actor 1 faces a wholesale price $w_{2}$ and fuzzy operational $\operatorname{cost} \tilde{c}_{1}$. Furthermore, actor 1 sells his product to the customers with retail price $p$, and can choose his order quantity $q$. Let $\tilde{\Pi}_{1}$ be the fuzzy profit for supply chain actor $1, \tilde{\Pi}_{i}$ be the fuzzy profit for actor $i, i=2,3, \ldots, n$, and $\tilde{\Pi}_{S C}$ be the fuzzy profit for whole supply chain.

The assumptions related to this paper are given as follows:

Assumption 1(Risk neutral assumption). The supply chain actors are all risk neutral, and they maximize the fuzzy expected profits.

Assumption 2(Positive assumption). We assume $w_{i}>w_{i+1}+E\left[\tilde{c}_{i}\right], \quad i=2,3, \ldots, n$, and $p>\sum_{i=1}^{n} E\left[\tilde{c}_{i}\right]$. These ensure that the supply chain actors can obtain their positive fuzzy profits.

\section{Fuzzy Supply Chain Models with Asymmetric Information}

In this section, we develop the centralized decisionmaking system and one coordinating contract, namely, RS contract with fuzzy demand and asymmetric information, which can tell the supply chain actors how to make their decisions in a fuzzy environment.

\subsection{Fuzzy centralized decision-making system with asymmetric information}

In the fuzzy centralized decision-making system, all the actors in the supply chain make cooperation, which can be regarded as the supply chain possessed by an integrated decision maker. Then, we can get the fuzzy profit function for supply chain system as

$$
\tilde{\Pi}_{S C}=\tilde{p} \min (q, \tilde{D})-\sum_{i=1}^{n} \tilde{c}_{i} q .
$$

The supply chain actors try to maximize their total fuzzy expected profit by setting the optimal order quantity $q$. Thus, the fuzzy model solved by the integrated decision maker is given by

$$
\begin{gathered}
\operatorname{Max}_{q} E\left[\tilde{\Pi}_{S C}\right]=E\left[\tilde{p} \min (q, \tilde{D})-\sum_{i=1}^{n} \tilde{c}_{i} q\right] \\
\text { s.t. } d_{1} \leq q \leq d_{3} .
\end{gathered}
$$

Since $\tilde{D}=\left(d_{1}, d_{2}, d_{3}\right)$ is a positive triangular fuzzy variable, then optimal order quantity $q$ set by the integrated decision maker has two cases, $q \in\left[d_{1}, d_{2}\right]$ and $q \in\left(d_{2}, d_{3}\right]$. 
Theorem 1. If $q \in\left[d_{1}, d_{2}\right]$, then the optimal order quantity $q^{*}$ satisfies the following equation

$$
\frac{1}{2} \int_{0}^{L\left(q^{*}\right)} \tilde{p}_{L}^{-1}(\alpha) \mathrm{d} \alpha=E[\tilde{p}]-\sum_{i=1}^{n} E\left[\tilde{c}_{i}\right] .
$$

Proof. If $q \in\left[d_{1}, d_{2}\right]$, then the $\alpha$ cut set of $\min (q, \tilde{D})$ is

$$
(\min (q, \tilde{D}))(\alpha)= \begin{cases}{\left[L^{-1}(\alpha), q\right],} & \alpha \in[0, L(q)] \\ {[q, q],} & \alpha \in(L(q), 1] .\end{cases}
$$

If $\alpha \in[0, L(q)]$, we can get the $\alpha$ cut set of $\tilde{\Pi}_{S C}(\alpha)$ as

$$
\begin{aligned}
\tilde{\Pi}_{S C}(\alpha)= & {\left[\tilde{p}_{L}^{-1}(\alpha) L^{-1}(\alpha), \tilde{p}_{R}^{-1}(\alpha) q\right] } \\
& -\left[\sum_{i=1}^{n} \tilde{c}_{i L}^{-1}(\alpha) q, \sum_{i=1}^{n} c_{i R}^{-1}(\alpha) q\right] \\
= & {\left[\tilde{p}_{L}^{-1}(\alpha) L^{-1}(\alpha)-\sum_{i=1}^{n} c_{i R}^{-1}(\alpha) q,\right.} \\
& \left.\tilde{p}_{R}^{-1}(\alpha) q-\sum_{i=1}^{n} \tilde{c}_{i L}^{-1}(\alpha) q\right] .
\end{aligned}
$$

If $\alpha \in(L(q), 1]$, we can get the $\alpha$ cut set of $\tilde{\Pi}_{S C}(\alpha)$ as

$$
\begin{aligned}
& \tilde{\Pi}_{S C}(\alpha)= {\left[\tilde{p}_{L}^{-1}(\alpha) q, \tilde{p}_{R}^{-1}(\alpha) q\right] } \\
&-\left[\sum_{i=1}^{n} \tilde{c}_{i L}^{-1}(\alpha) q, \sum_{i=1}^{n} c_{i R}^{-1}(\alpha) q\right] \\
&= {\left[\tilde{p}_{L}^{-1}(\alpha) q-\sum_{i=1}^{n} c_{i R}^{-1}(\alpha) q,\right.} \\
&\left.\tilde{p}_{R}^{-1}(\alpha) q-\sum_{i=1}^{n} \tilde{c}_{i L}^{-1}(\alpha) q\right] .
\end{aligned}
$$

From Eq.(6), the fuzzy expected profit $E\left[\tilde{\Pi}_{S C}\right]$ can be obtained as

$$
\begin{gathered}
E\left[\tilde{\Pi}_{S C}\right]=\frac{1}{2} \int_{0}^{L(q)}\left(\tilde{p}_{L}^{-1}(\alpha) L^{-1}(\alpha)-\sum_{i=1}^{n} c_{i R}^{-1}(\alpha) q\right. \\
\left.+\tilde{p}_{R}^{-1}(\alpha) q-\sum_{i=1}^{n} \tilde{c}_{i L}^{-1}(\alpha) q\right) \mathrm{d} \alpha \\
+\frac{1}{2} \int_{L(q)}^{1}\left(\tilde{p}_{L}^{-1}(\alpha) q-\sum_{i=1}^{n} c_{i R}^{-1}(\alpha) q\right. \\
\left.+\tilde{p}_{R}^{-1}(\alpha) q-\sum_{i=1}^{n} \tilde{c}_{i L}^{-1}(\alpha) q\right) \mathrm{d} \alpha \\
=-\frac{1}{2} \int_{0}^{L(q)} \tilde{p}_{L}^{-1}(\alpha)\left(q-L^{-1}(\alpha)\right) \mathrm{d} \alpha
\end{gathered}
$$

$$
+\left(E[\tilde{p}]-\sum_{i=1}^{n} E\left[\tilde{c}_{i}\right]\right) q
$$

From Eq.(13), the first order condition of $E\left[\tilde{\Pi}_{S C}\right]$ is

$$
\frac{\mathrm{d} E\left[\tilde{\Pi}_{S C}\right]}{\mathrm{d} q}=-\frac{1}{2} \int_{0}^{L(q)} \tilde{p}_{L}^{-1}(\alpha) \mathrm{d} \alpha+E[\tilde{p}]-\sum_{i=1}^{n} E\left[\tilde{c}_{i}\right] .
$$

The second order condition of $E\left[\tilde{\Pi}_{S C}\right]$ is

$$
\frac{\mathrm{d}^{2} E\left[\tilde{\Pi}_{S C}\right]}{\mathrm{d} q^{2}}=-\frac{1}{2} \tilde{p}_{L}^{-1}(L(q)) L^{\prime}(q)
$$

Note that the second order condition is negative, since $L(q)$ is increasing about $q$ with $L^{\prime}(q)>0$ and $\tilde{p}_{L}^{-1}(L(q))>0$. Therefore, $E\left[\tilde{\Pi}_{S C}\right]$ is a concave function with respect to $q$.

Hence, we can get the optimal order quantity $q^{*}$ by letting the first order condition be zero

$$
-\frac{1}{2} \int_{0}^{L(q)} \tilde{p}_{L}^{-1}(\alpha) \mathrm{d} \alpha+E[\tilde{p}]-\sum_{i=1}^{n} E\left[\tilde{c}_{i}\right]=0 .
$$

Solving Eq.(14), we can get $q^{*}$ as shown in Eq.(12). Theorem 1 is proved.

Theorem 2. If $q \in\left(d_{2}, d_{3}\right]$, then the optimal order quantity $q^{*}$ satisfies the following equation

$$
\frac{1}{2} \int_{0}^{R\left(q^{*}\right)} \tilde{p}_{R}^{-1}(\alpha) \mathrm{d} \alpha=\sum_{i=1}^{n} E\left[\tilde{c}_{i}\right]
$$

Proof. If $q \in\left(d_{2}, d_{3}\right]$, then the $\alpha$ cut set of $\min (q, \tilde{D})$ is

$$
(\min (q, \tilde{D}))(\alpha)= \begin{cases}{\left[L^{-1}(\alpha), q\right],} & \alpha \in[0, R(q)], \\ {\left[L^{-1}(\alpha), R^{-1}(\alpha)\right],} & \alpha \in(R(q), 1] .\end{cases}
$$

If $\alpha \in[0, R(q)]$, we can get the $\alpha$ cut set of $\tilde{\Pi}_{S C}(\alpha)$ as

$$
\begin{aligned}
\tilde{\Pi}_{S C}(\alpha)= & {\left[\tilde{p}_{L}^{-1}(\alpha) L^{-1}(\alpha), \tilde{p}_{R}^{-1}(\alpha) q\right] } \\
& -\left[\sum_{i=1}^{n} \tilde{c}_{i L}^{-1}(\alpha) q, \sum_{i=1}^{n} c_{i R}^{-1}(\alpha) q\right] \\
= & {\left[\tilde{p}_{L}^{-1}(\alpha) L^{-1}(\alpha)-\sum_{i=1}^{n} c_{i R}^{-1}(\alpha) q,\right.} \\
& \left.\tilde{p}_{R}^{-1}(\alpha) q-\sum_{i=1}^{n} \tilde{c}_{i L}^{-1}(\alpha) q\right] .
\end{aligned}
$$

If $\alpha \in(R(q), 1]$, we can get the $\alpha$ cut set of $\tilde{\Pi}_{S C}(\alpha)$ as

$$
\tilde{\Pi}_{S C}(\alpha)=\left[\tilde{p}_{L}^{-1}(\alpha) L^{-1}(\alpha), \tilde{p}_{R}^{-1}(\alpha) R^{-1}(\alpha)\right]
$$




$$
\begin{aligned}
& -\left[\sum_{i=1}^{n} \tilde{c}_{i L}^{-1}(\alpha) q, \sum_{i=1}^{n} \tilde{c}_{i R}^{-1}(\alpha) q\right] \\
= & {\left[\tilde{p}_{L}^{-1}(\alpha) L^{-1}(\alpha)-\sum_{i=1}^{n} c_{i R}^{-1}(\alpha) q,\right.} \\
& \left.\tilde{p}_{R}^{-1}(\alpha) R^{-1}(\alpha)-\sum_{i=1}^{n} \tilde{c}_{i L}^{-1}(\alpha) q\right] .
\end{aligned}
$$

From Eq.(6), the fuzzy expected profit $E\left[\tilde{\Pi}_{S C}\right]$ can be obtained as

$$
\begin{aligned}
E\left[\tilde{\Pi}_{S C}\right]= & \frac{1}{2} \int_{0}^{R(q)}\left(\tilde{p}_{L}^{-1}(\alpha) L^{-1}(\alpha)-\sum_{i=1}^{n} \tilde{c}_{i L}^{-1}(\alpha) q\right. \\
& \left.+\tilde{p}_{R}^{-1}(\alpha) q-\sum_{i=1}^{n} \tilde{c}_{i L}^{-1}(\alpha) q\right) \mathrm{d} \alpha \\
& +\frac{1}{2} \int_{R(q)}^{1}\left(\tilde{p}_{L}^{-1}(\alpha) L^{-1}(\alpha)-\sum_{i=1}^{n} \tilde{c}_{i R}^{-1}(\alpha) q\right. \\
& \left.+\tilde{p}_{R}^{-1}(\alpha) R^{-1}(\alpha)-\sum_{i=1}^{n} \tilde{c}_{i L}^{-1}(\alpha) q\right) \mathrm{d} \alpha \\
= & \frac{1}{2} \int_{0}^{R(q)} \tilde{p}_{R}^{-1}(\alpha)\left(q-R^{-1}(\alpha)\right) \mathrm{d} \alpha \\
& +E[\tilde{p} \tilde{D}]-\sum_{i=1}^{n} E\left[\tilde{c}_{i}\right] q .
\end{aligned}
$$

From Eq.(16), the first order condition of $E\left[\tilde{\Pi}_{S C}\right]$ is

$$
\frac{\mathrm{d} E\left[\tilde{\Pi}_{S C}\right]}{\mathrm{d} q}=\frac{1}{2} \int_{0}^{R(q)} \tilde{p}_{R}^{-1}(\alpha) \mathrm{d} \alpha-\sum_{i=1}^{n} E\left[\tilde{c}_{i}\right] .
$$

The second order condition of $E\left[\tilde{\Pi}_{S C}\right]$ is

$$
\frac{\mathrm{d}^{2} E\left[\tilde{\Pi}_{S C}\right]}{\mathrm{d} q^{2}}=\frac{1}{2} \tilde{p}_{R}^{-1}(R(q)) R^{\prime}(q) .
$$

Note that the second order condition is negative, since $R(q)$ is decreasing about $q$ with $R^{\prime}(q)<0$ and $\tilde{p}_{R}^{-1}(R(q))>0$. Therefore, $E\left[\tilde{\Pi}_{S C}\right]$ is a concave function with respect to $q$.

Hence, we can get the optimal order quantity $q^{*}$ by letting the first order condition be zero

$$
\frac{1}{2} \int_{0}^{R(q)} \tilde{p}_{R}^{-1}(\alpha) \mathrm{d} \alpha-\sum_{i=1}^{n} E\left[\tilde{c}_{i}\right]=0 .
$$

Solving Eq.(17), we can get $q^{*}$ as shown in Eq.(15). Theorem 2 is proved.

Theorem 3. If $\tilde{p}=\left(p-\Delta_{1}, p, p+\Delta_{2}\right)$, then the optimal order quantity $q^{*}$ can be expressed as

(1) if $p \in\left(\sum_{i=1}^{n} E\left[\tilde{c}_{i}\right], 2 \sum_{i=1}^{n} E\left[\tilde{c}_{i}\right]-0.5 \Delta_{2}\right]$, then

$$
q^{*}=L^{-1}\left(\frac{\sqrt{0.25\left(p-\Delta_{1}\right)^{2}+\left(p+0.25 \Delta_{2}-0.25 \Delta_{1}-\sum_{i=1}^{n} E\left[\tilde{c}_{i}\right]\right) \Delta_{1}}-0.5\left(p-\Delta_{1}\right)}{0.5 \Delta_{1}}\right) .
$$

(2) if $p \in\left(2 \sum_{i=1}^{n} E\left[\tilde{c}_{i}\right]-0.5 \Delta_{2},+\infty\right)$, then

$$
q^{*}=R^{-1}\left(\frac{0.5\left(p+\Delta_{2}\right)-\sqrt{0.25\left(p+\Delta_{2}\right)^{2}-\sum_{i=1}^{n} E\left[\tilde{c}_{i}\right] \Delta_{2}}}{0.5 \Delta_{2}}\right) .
$$

Proof. If $\tilde{p}=\left(p-\Delta_{1}, p, p+\Delta_{2}\right)$, then left and right cut set boundary of $\tilde{p}$ with $\tilde{p}_{L}^{-1}(\alpha)$ and $\tilde{p}_{R}^{-1}(\alpha)$, respectively, are

$$
\tilde{p}_{L}^{-1}(\alpha)=p-(1-\alpha) \Delta_{1}, \text { and } \tilde{p}_{R}^{-1}(\alpha)=p+(1-\alpha) \Delta_{2} .
$$

Case 1. $q \in\left[d_{1}, d_{2}\right]$

Substituting $\tilde{p}_{L}^{-1}(\alpha)$ and $\tilde{p}_{R}^{-1}(\alpha)$ into Eq. (12), we have

$$
\begin{gathered}
0.25 \Delta_{1} L^{2}\left(q^{*}\right)+0.5\left(p-\Delta_{1}\right) L\left(q^{*}\right)-p \\
-0.25 \Delta_{2}+0.25 \Delta_{1}+\sum_{i=1}^{n} E\left[\tilde{c}_{i}\right]=0
\end{gathered}
$$

Solving Eq.(18) leads to

$$
L\left(q^{*}\right)=\frac{\sqrt{0.25\left(p-\Delta_{1}\right)^{2}+\left(p+0.25 \Delta_{2}-0.25 \Delta_{1}-\sum_{i=1}^{n} E\left[\tilde{c}_{i}\right]\right) \Delta_{1}}-0.5\left(p-\Delta_{1}\right)}{0.5 \Delta_{1}} .
$$

Since $0 \leq L\left(q^{*}\right) \leq 1$, thus we get $p \leq 2 \sum_{i=1}^{n} E\left[\tilde{c}_{i}\right]-0.5 \Delta_{2}$. Case 2. $q \in\left(d_{2}, d_{3}\right]$

Substituting $\tilde{p}_{L}^{-1}(\alpha)$ and $\tilde{p}_{R}^{-1}(\alpha)$ into Eq. (15), we have

$0.25 \Delta_{2} R^{2}\left(q^{*}\right)-0.5\left(p+\Delta_{2}\right) R\left(q^{*}\right)+\sum_{i=1}^{n} E\left[\tilde{c}_{i}\right]=0$.

Solving Eq.(20) leads to

$R\left(q^{*}\right)=\frac{0.5\left(p+\Delta_{2}\right)-\sqrt{0.25\left(p+\Delta_{2}\right)^{2}-\sum_{i=1}^{n} E\left[\tilde{c}_{i}\right] \Delta_{2}}}{0.5 \Delta_{2}}$

Since $0 \leq R\left(q^{*}\right) \leq 1$, thus we get $p>2 \sum_{i=1}^{n} E\left[\tilde{c}_{i}\right]-0.5 \Delta_{2}$.

Note that if $p=2 \sum_{i=1}^{n} E\left[\tilde{c}_{i}\right]-0.5 \Delta_{2}$, and then we have the following equation

$$
\begin{aligned}
& \frac{\sqrt{0.25\left(p-\Delta_{1}\right)^{2}+\left(p+0.25 \Delta_{2}-0.25 \Delta_{1}-\sum_{i=1}^{n} E\left[\tilde{c}_{i}\right]\right) \Delta_{1}}-0.5\left(p-\Delta_{1}\right)}{0.5 \Delta_{1}} \\
= & \frac{0.5\left(p+\Delta_{2}\right)-\sqrt{0.25\left(p+\Delta_{2}\right)^{2}-\sum_{i=1}^{n} E\left[\tilde{c}_{i}\right] \Delta_{2}}}{0.5 \Delta_{2}} .
\end{aligned}
$$


That is $L\left(q^{*}\right)=R\left(q^{*}\right)$.

Theorem 3 is proved.

Theorem 4. If $\Delta_{1} \rightarrow 0$ and $\Delta_{2} \rightarrow 0$, then the retail price $\tilde{p}$ reduces to the crisp real number, the results in Theorem 3 are reduced to

$q^{*}= \begin{cases}L^{-1}\left(\frac{2\left(p-\sum_{i=1}^{n} E\left[\tilde{c}_{i}\right]\right)}{p}\right), & p \in\left(\sum_{i=1}^{n} E\left[\tilde{c}_{i}\right], 2 \sum_{i=1}^{n} E\left[\tilde{c}_{i}\right]\right], \\ R^{-1}\left(\frac{2 \sum_{i=1}^{n} E\left[\tilde{c}_{i}\right]}{p}\right), & p \in\left(2 \sum_{i=1}^{n} E\left[\tilde{c}_{i}\right],+\infty\right) .\end{cases}$

There are just the solutions with symmetric information.

Proof. Case 1. $q \in\left[d_{1}, d_{2}\right]$

If $q \in\left[d_{1}, d_{2}\right]$, that is $p \in\left(\sum_{i=1}^{n} E\left[\tilde{c}_{i}\right], 2 \sum_{i=1}^{n} E\left[\tilde{c}_{i}\right]\right]$, then let $\Delta_{1} \rightarrow 0$ and $\Delta_{2} \rightarrow 0$, we can get

$q^{*}=\lim _{\Delta_{1} \rightarrow 0, \Delta_{2} \rightarrow 0} L^{-1}\left(\frac{\sqrt{0.25\left(p-\Delta_{1}\right)^{2}+\left(p+0.25 \Delta_{2}-0.25 \Delta_{1}-\sum_{i=1}^{n} E\left[\tilde{c}_{i}\right]\right) \Delta_{1}}-0.5\left(p-\Delta_{1}\right)}{0.5 \Delta_{1}}\right)$

$=\lim _{\Delta_{1} \rightarrow 0, \Delta_{2} \rightarrow 0} L^{-1}\left(\frac{\frac{0.5 p+0.25 \Delta_{2}-\sum_{i=1}^{n} E\left[\tilde{c}_{i}\right]}{\sqrt{0.25\left(p-\Delta_{1}\right)^{2}+\left(p+0.25 \Delta_{2}-0.25 \Delta_{1}-\sum_{i=1}^{n} E\left[\tilde{c}_{i}\right]\right) \Delta_{1}}}+0.5}{0.5}\right)$

$=L^{-1}\left(\frac{2\left(p-\sum_{i=1}^{n} E\left[\tilde{c}_{i}\right]\right)}{p}\right)$.

Case 2. $q \in\left(d_{2}, d_{3}\right]$

If $q \in\left(d_{2}, d_{3}\right]$, that is $p \in\left(2 \sum_{i=1}^{n} E\left[\tilde{c}_{i}\right],+\infty\right)$, then let $\Delta_{1} \rightarrow 0$ and $\Delta_{2} \rightarrow 0$, we can get

$$
\begin{aligned}
q^{*} & =\lim _{\Delta_{2} \rightarrow 0} R^{-1}\left(\frac{0.5\left(p+\Delta_{2}\right)-\sqrt{0.25\left(p+\Delta_{2}\right)^{2}-\sum_{i=1}^{n} E\left[\tilde{c}_{i}\right] \Delta_{2}}}{0.5 \Delta_{2}}\right) \\
& =\lim _{\Delta_{2} \rightarrow 0} R^{-1}\left(\frac{0.5-\frac{0.5\left(p+\Delta_{2}\right)-\sum_{i=1}^{n} E\left[\tilde{c}_{i}\right]}{2 \sqrt{0.25\left(p+\Delta_{2}\right)^{2}-\sum_{i=1}^{n} E\left[\tilde{c}_{i}\right] \Delta_{2}}}}{0.5}\right) \\
& =R^{-1}\left(\frac{2 \sum_{i=1}^{n} E\left[\tilde{c}_{i}\right]}{p}\right) .
\end{aligned}
$$

Theorem 4 is proved.
From Eqs.(13), (16) and (18), we can easily derive the optimal fuzzy expected profits for supply chain system as follows

Case 1. $p \in\left(\sum_{i=1}^{n} E\left[\tilde{c}_{i}\right], 2 \sum_{i=1}^{n} E\left[\tilde{c}_{i}\right]-0.5 \Delta_{2}\right]$

$$
E\left[\tilde{\Pi}_{S C}\right]^{*}=\frac{1}{2} \int_{0}^{L\left(q^{*}\right)} \tilde{p}_{L}^{-1}(\alpha) L^{-1}(\alpha) \mathrm{d} \alpha
$$

where

$q^{*}=L^{-1}\left(\frac{\sqrt{0.25\left(p-\Delta_{1}\right)^{2}+\left(p+0.25 \Delta_{2}-0.25 \Delta_{1}-\sum_{i=1}^{n} E\left[\tilde{c}_{i}\right]\right) \Delta_{1}}-0.5\left(p-\Delta_{1}\right)}{0.5 \Delta_{1}}\right)$.

Case 2. $p \in\left(2 \sum_{i=1}^{n} E\left[\tilde{c}_{i}\right]-0.5 \Delta_{2},+\infty\right)$

$$
E\left[\tilde{\Pi}_{S C}\right]^{*}=E[\tilde{p} \tilde{D}]-\frac{1}{2} \int_{0}^{R\left(q^{*}\right)} \tilde{p}_{R}^{-1}(\alpha) R^{-1}(\alpha) \mathrm{d} \alpha .
$$

where

$$
q^{*}=R^{-1}\left(\frac{0.5\left(p+\Delta_{2}\right)-\sqrt{0.25\left(p+\Delta_{2}\right)^{2}-\sum_{i=1}^{n} E\left[\tilde{c}_{i}\right] \Delta_{2}}}{0.5 \Delta_{2}}\right) .
$$

\subsection{Fuzzy revenue sharing contract with asymmetric information}

In the RS contract, the supply chain actor 1 shares his fuzzy profit with other actor $i, i=2,3, \ldots, n$, and the portion is denoted by $\Phi_{i}$, with $\Phi_{i} \in(0,1)$. Then the portion kept by the actor 1 is $1-\sum_{i=2}^{n} \Phi_{i}$, with $\sum_{i=2}^{n} \Phi_{i} \in(0,1)$.

Thus, the fuzzy profit function for actor 1 can be expressed as follows

$$
\tilde{\Pi}_{1}=\left(1-\sum_{i=2}^{n} \Phi_{i}\right) \tilde{p} \min (q, \tilde{D})-\left(w_{2}+\tilde{c}_{1}\right) q .
$$

The supply chain actor 1 wants to get the order quantity $q$ which maximizes his expected profit $E\left[\tilde{\Pi}_{1}\right]$. Thus, the optimal objection function of actor 1 is

$$
\begin{aligned}
& \operatorname{Max}_{q} E\left[\tilde{\Pi}_{1}\right]=E\left[\left(1-\sum_{i=2}^{n} \Phi_{i}\right) \tilde{p} \min (q, \tilde{D})-\left(w_{2}+\tilde{c}_{1}\right) q\right] \\
& \text { s.t. } d_{1} \leq q \leq d_{3} .
\end{aligned}
$$

In the RS contract, we can also get the profit function for supply chain actor $i, i=2,3, \ldots, n$, as 


$$
\tilde{\Pi}_{i}=\Phi_{i} \tilde{p} \min (q, \tilde{D})+\left(w_{i}-w_{i+1}-\tilde{c}_{i}\right) q
$$

The supply chain actor $i, i=2,3, \ldots, n$, also wants to maximize the expected profit $E\left[\tilde{\Pi}_{i}\right]$.thus, the optimal objection function of actor $i$ is

$$
\begin{gathered}
\operatorname{Max}_{q} E\left[\tilde{\Pi}_{i}\right]=E\left[\Phi_{i} \tilde{p} \min (q, \tilde{D})+\left(w_{i}-w_{i+1}-\tilde{c}_{i}\right) q\right] \\
\text { s.t. } d_{1} \leq q \leq d_{3} .
\end{gathered}
$$

Theorem 5. The optimal wholesale price $w_{i}{ }^{*}$ $(i=2,3, \ldots, n)$ that the actor $i$ charges the actor $i-1$, in the RS contract satisfies the following equations

$$
\begin{aligned}
& w_{2}^{*}=\left(1-\sum_{i=2}^{n} \Phi_{i}\right) \sum_{i=1}^{n} E\left[\tilde{c}_{i}\right]-E\left[\tilde{c}_{1}\right] \\
& {w_{i+1}}^{*}=w_{i}^{*}-E\left[\tilde{c}_{i}\right]+\Phi_{i} \sum_{i=1}^{n} E\left[\tilde{c}_{i}\right] \text { and } w_{n+1}=0 .
\end{aligned}
$$

Proof. Case 1. $q \in\left[d_{1}, d_{2}\right]$

Similar to the solution process in Eq.(13), the fuzzy expected profit for supply chain actor 1 can be easily obtained as follows

$$
\begin{aligned}
E\left[\tilde{\Pi}_{1}\right]=- & \frac{1}{2}\left(1-\sum_{i=2}^{n} \Phi_{i}\right) \int_{0}^{L(q)} \tilde{p}_{L}^{-1}(\alpha)\left(q-L^{-1}(\alpha)\right) \mathrm{d} \alpha \\
& +\left(\left(1-\sum_{i=2}^{n} \Phi_{i}\right) E[\tilde{p}]-w_{2}-E\left[\tilde{c}_{1}\right]\right) q
\end{aligned}
$$

From Eq.(31), the first order condition of $E\left[\tilde{\Pi}_{1}\right]$ is

$$
\begin{aligned}
\frac{\mathrm{d} E\left[\tilde{\Pi}_{1}\right]}{\mathrm{d} q}= & -\frac{1}{2}\left(1-\sum_{i=2}^{n} \Phi_{i}\right) \int_{0}^{L(q)} \tilde{p}_{L}^{-1}(\alpha) \mathrm{d} \alpha \\
& +\left(1-\sum_{i=2}^{n} \Phi_{i}\right) E[\tilde{p}]-w_{2}-E\left[\tilde{c}_{1}\right]
\end{aligned}
$$

The second order condition of $E\left[\tilde{\Pi}_{1}\right]$ is

$$
\frac{\mathrm{d}^{2} E\left[\tilde{\Pi}_{1}\right]}{\mathrm{d} q^{2}}=-\frac{1}{2}\left(1-\sum_{i=2}^{n} \Phi_{i}\right) \tilde{p}_{L}^{-1}(L(q)) L^{\prime}(q) .
$$

Note that the second order condition is negative, since $L(q)$ is increasing about $q$ with $L^{\prime}(q)>0$, $1-\sum_{i=2}^{n} \Phi_{i}>0$ and $\tilde{p}_{L}^{-1}(L(q))>0$. Therefore, $E\left[\tilde{\Pi}_{1}\right]$ is a concave function with respect to $q$.

Hence, we can get the optimal order quantity $q^{* *}$ by letting the first order condition be zero

$$
-\frac{1}{2}\left(1-\sum_{i=2}^{n} \Phi_{i}\right) \int_{0}^{L\left(q^{* *}\right)} \tilde{p}_{L}^{-1}(\alpha) \mathrm{d} \alpha
$$

$$
+\left(1-\sum_{i=2}^{n} \Phi_{i}\right) E[\tilde{p}]-w_{2}-E\left[\tilde{c}_{1}\right]=0
$$

That is

$$
\frac{1}{2} \int_{0}^{L\left(q^{* *}\right)} \tilde{p}_{L}^{-1}(\alpha) \mathrm{d} \alpha=E[\tilde{p}]-\frac{w_{2}+E\left[\tilde{c}_{1}\right]}{1-\sum_{i=2}^{n} \Phi_{i}}
$$

For coordinating this supply chain, $q^{* *}=q^{*}$ must be hold. This means that the optimal order chosen by supply chain actor 1 in fuzzy RS contract is the same as in fuzzy centralized decision-making system.

Comparing Eq.(31) with Eq.(12), we have

$$
w_{2}{ }^{*}=\left(1-\sum_{i=2}^{n} \Phi_{i}\right) \sum_{i=1}^{n} E\left[\tilde{c}_{i}\right]-E\left[\tilde{c}_{1}\right]
$$

Similar to the solution process in Eq.(13), we can also easily obtain the fuzzy expected profit for supply chain actor $i$ as

$$
\begin{aligned}
E\left[\tilde{\Pi}_{i}\right]= & -\frac{1}{2} \Phi_{i} \int_{0}^{L(q)} \tilde{p}_{L}^{-1}(\alpha)\left(q-L^{-1}(\alpha)\right) \mathrm{d} \alpha \\
& +\left(\Phi_{i} E[\tilde{p}]+w_{i}-w_{i+1}-E\left[\tilde{c}_{i}\right]\right) q
\end{aligned}
$$

From Eq.(32), the first order condition of $E\left[\tilde{\Pi}_{i}\right]$ is

$\frac{\mathrm{d} E\left[\tilde{\Pi}_{i}\right]}{\mathrm{d} q}=-\frac{1}{2} \Phi_{i} \int_{0}^{L(q)} \tilde{p}_{L}^{-1}(\alpha) \mathrm{d} \alpha+\Phi_{i} E[\tilde{p}]+w_{i}-w_{i+1}-E\left[\tilde{c}_{i}\right]$

The second order condition of $E\left[\tilde{\Pi}_{i}\right]$ is

$$
\frac{\mathrm{d}^{2} E\left[\tilde{\Pi}_{i}\right]}{\mathrm{d} q^{2}}=-\frac{1}{2} \Phi_{i} \tilde{p}_{L}^{-1}(L(q)) L^{\prime}(q)
$$

Note that the second order condition is negative, since $L(q)$ is increasing about $q$ with $L^{\prime}(q)>0, \Phi_{i}>0$ and $\tilde{p}_{L}^{-1}(L(q))>0$. Therefore, $E\left[\tilde{\Pi}_{i}\right]$ is a concave function with respect to $q$.

Hence, we can get the optimal order quantity $q^{* *}$ by letting the first order condition be zero

$$
-\frac{1}{2} \Phi_{i} \int_{0}^{L\left(q^{* *}\right)} \tilde{p}_{L}^{-1}(\alpha) \mathrm{d} \alpha+\Phi_{i} E[\tilde{p}]+w_{i}-w_{i+1}-E\left[\tilde{c}_{i}\right]=0
$$

That is

$$
\frac{1}{2} \int_{0}^{L\left(q^{* *}\right)} \tilde{p}_{L}^{-1}(\alpha) \mathrm{d} \alpha=E[\tilde{p}]+\frac{w_{i}-w_{i+1}-E\left[\tilde{c}_{i}\right]}{\Phi_{i}} .
$$

For coordinating this supply chain system, $q^{* *}=q^{*}$ must be hold.

Comparing Eq.(34) with Eq.(12), we have 


$$
w_{i+1}^{*}=w_{i}^{*}-E\left[\tilde{c}_{i}\right]+\Phi_{i} \sum_{i=1}^{n} E\left[\tilde{c}_{i}\right]
$$

Case 2. $q \in\left(d_{2}, d_{3}\right]$

Similar to the solution process in Eq.(16), the fuzzy expected profit for supply chain actor $1 E\left[\tilde{\Pi}_{1}\right]$ is

$$
\begin{aligned}
E\left[\tilde{\Pi}_{1}\right] & =\frac{1}{2}\left(1-\sum_{i=2}^{n} \Phi_{i}\right) \int_{0}^{R(q)} \tilde{p}_{R}^{-1}(\alpha)\left(q-R^{-1}(\alpha)\right) \mathrm{d} \alpha \\
& +\left(1-\sum_{i=2}^{n} \Phi_{i}\right) E[\tilde{p} \tilde{D}]-\left(w_{2}+E\left[\tilde{c}_{1}\right]\right) q
\end{aligned}
$$

From Eq.(35), the first order condition of $E\left[\tilde{\Pi}_{1}\right]$ is

$$
\frac{\mathrm{d} E\left[\tilde{\Pi}_{1}\right]}{\mathrm{d} q}=\frac{1}{2}\left(1-\sum_{i=2}^{n} \Phi_{i}\right) \int_{0}^{R(q)} \tilde{p}_{R}^{-1}(\alpha) \mathrm{d} \alpha-w_{2}-E\left[\tilde{c}_{1}\right] .
$$

The second order condition of $E\left[\tilde{\Pi}_{1}\right]$ is

$$
\frac{\mathrm{d}^{2} E\left[\tilde{\Pi}_{1}\right]}{\mathrm{d} q^{2}}=\frac{1}{2}\left(1-\sum_{i=2}^{n} \Phi_{i}\right) \tilde{p}_{R}^{-1}(R(q)) R^{\prime}(q) .
$$

Note that the second order condition is negative, since $R(q)$ is decreasing about $q$ with $R^{\prime}(q)<0$, $1-\sum_{i=2}^{n} \Phi_{i}>0$ and $\tilde{p}_{R}^{-1}(R(q))>0$. Therefore, $E\left[\tilde{\Pi}_{1}\right]$ is a concave function with respect to $q$.

Hence, we can get the optimal order quantity $q^{* *}$ by letting the first order condition be zero

$$
\frac{1}{2}\left(1-\sum_{i=2}^{n} \Phi_{i}\right) \int_{0}^{R\left(q^{* *}\right)} \tilde{p}_{R}^{-1}(\alpha) \mathrm{d} \alpha-w_{2}-E\left[\tilde{c}_{1}\right]=0 .
$$

That is

$$
\frac{1}{2} \int_{0}^{R\left(q^{* *}\right)} \tilde{p}_{R}^{-1}(\alpha) \mathrm{d} \alpha=\frac{w_{2}+E\left[\tilde{c}_{1}\right]}{1-\sum_{i=2}^{n} \Phi_{i}} .
$$

For coordinating this supply chain, $q^{* *}=q^{*}$ must be hold.

Comparing Eq.(37) with Eq.(15), we have

$$
w_{2}{ }^{*}=\left(1-\sum_{i=2}^{n} \Phi_{i}\right) \sum_{i=1}^{n} E\left[\tilde{c}_{i}\right]-E\left[\tilde{c}_{1}\right]
$$

Similar to the solution process in Eq.(16), the fuzzy expected profit for supply chain actor $i E\left[\tilde{\Pi}_{i}\right]$ is

$$
\begin{aligned}
E\left[\tilde{\Pi}_{i}\right]= & \frac{1}{2} \Phi_{i} \int_{0}^{R(q)} \tilde{p}_{R}^{-1}(\alpha)\left(q-R^{-1}(\alpha)\right) \mathrm{d} \alpha \\
& +\Phi_{i} E[\tilde{p} \tilde{D}]+\left(w_{i}-w_{i+1}-E\left[\tilde{c}_{i}\right]\right) q .
\end{aligned}
$$

From Eq.(38), the first order condition of $E\left[\tilde{\Pi}_{i}\right]$ is

$$
\frac{\mathrm{d} E\left[\tilde{\Pi}_{i}\right]}{\mathrm{d} q}=\frac{1}{2} \Phi_{i} \int_{0}^{R(q)} \tilde{p}_{R}^{-1}(\alpha) \mathrm{d} \alpha+w_{i}-w_{i+1}-E\left[\tilde{c}_{i}\right] .
$$

The second order condition of $E\left[\tilde{\Pi}_{i}\right]$ is

$$
\frac{\mathrm{d}^{2} E\left[\tilde{\Pi}_{i}\right]}{\mathrm{d} q^{2}}=\frac{1}{2} \Phi_{i} \tilde{p}_{R}^{-1}(R(q)) R^{\prime}(q) .
$$

Note that the second order condition is negative, since $R(q)$ is decreasing about $q$ with $R^{\prime}(q)<0, \Phi_{i}>0$ and $\tilde{p}_{R}^{-1}(R(q))>0$. Therefore, $E\left[\tilde{\Pi}_{i}\right]$ is a concave function with respect to $q$.

Hence, we can get the optimal order quantity $q^{* *}$ by letting the first order condition be zero

$$
\frac{1}{2} \Phi_{i} \int_{0}^{R(q)} \tilde{p}_{R}^{-1}(\alpha) \mathrm{d} \alpha+w_{i}-w_{i+1}-E\left[\tilde{c}_{i}\right]=0 .
$$

That is

$$
\frac{1}{2} \int_{0}^{R\left(q^{* *}\right)} \tilde{p}_{R}^{-1}(\alpha) \mathrm{d} \alpha=\frac{w_{i+1}-w_{i}+E\left[\tilde{c}_{i}\right]}{\Phi_{i}} .
$$

For coordinating this supply chain system, $q^{* *}=q^{*}$ must hold.

Comparing Eq.(40) with Eq.(15), we have

$$
w_{i+1}{ }^{*}=w_{i}^{*}-E\left[\tilde{c}_{i}\right]+\Phi_{i} \sum_{i=1}^{n} E\left[\tilde{c}_{i}\right] .
$$

Theorem 5 is proved.

Theorem 6. In fuzzy RS contract, the supply chain actor 1 and actor $i, i=2,3, \ldots, n$, obtain their optimal fuzzy profits at $w_{i}^{*}$ as follows

$$
\begin{aligned}
& E\left[\tilde{\Pi}_{1}\right]^{*}=\left(1-\sum_{i=2}^{n} \Phi_{i}\right) E\left[\tilde{\Pi}_{S C}\right]^{*}, \\
& E\left[\tilde{\Pi}_{i}\right]^{*}=\Phi_{i} E\left[\tilde{\Pi}_{S C}\right]^{*} .
\end{aligned}
$$

Proof. Case 1. $q \in\left[d_{1}, d_{2}\right]$

Substituting $w_{2}{ }^{*}$ in Eq.(28) and $q^{* *}=q^{*}$ into Eq.(29), we have the optimal fuzzy profit for actor 1 in fuzzy RS contract as

$$
\begin{aligned}
E\left[\tilde{\Pi}_{1}\right]^{*} & =\frac{1}{2}\left(1-\sum_{i=2}^{n} \Phi_{i}\right) \int_{0}^{L\left(q^{*}\right)} \tilde{p}_{L}^{-1}(\alpha) L^{-1}(\alpha) \mathrm{d} \alpha \\
& =\left(1-\sum_{i=2}^{n} \Phi_{i}\right) E\left[\tilde{\Pi}_{S C}\right]^{*} .
\end{aligned}
$$

Substituting $w_{i+1}{ }^{*}$ in Eq.(28) and $q^{* *}=q^{*}$ into Eq.(32), we have the optimal fuzzy profit for actor $i$ as follows 


$$
\begin{aligned}
& E\left[\tilde{\Pi}_{i}\right]^{*}=\frac{1}{2} \Phi_{i}\left(1-\sum_{i=2}^{n} \Phi_{i}\right) \int_{0}^{L\left(q^{*}\right)} \tilde{p}_{L}^{-1}(\alpha) L^{-1}(\alpha) \mathrm{d} \alpha \\
= & \Phi_{i} E\left[\tilde{\Pi}_{S C}\right]^{*} .
\end{aligned}
$$

Case 2. $q \in\left(d_{2}, d_{3}\right]$

Substituting $w_{2}{ }^{*}$ in Eq.(28) and $q^{* *}=q^{*}$ into Eq.(35), we have the optimal fuzzy profit for actor 1 in fuzzy RS contract as

$$
\begin{gathered}
E\left[\tilde{\Pi}_{1}\right]^{*}=\left(1-\sum_{i=2}^{n} \Phi_{i}\right) E[\tilde{p} \tilde{D}] \\
-\frac{1}{2}\left(1-\sum_{i=2}^{n} \Phi_{i}\right) \int_{0}^{R\left(q^{*}\right)} \tilde{p}_{R}^{-1}(\alpha) R^{-1}(\alpha) \mathrm{d} \alpha \\
=\left(1-\sum_{i=2}^{n} \Phi_{i}\right) E\left[\tilde{\Pi}_{S C}\right]^{*} .
\end{gathered}
$$

Substituting $w_{i+1}{ }^{*}$ in Eq.(30) and $q^{* *}=q^{*}$ into Eq.(40), we have the optimal fuzzy profit for actor $i$ as follows

$$
\begin{aligned}
E\left[\tilde{\Pi}_{i}\right]^{*} & =\Phi_{i} E[\tilde{p} \tilde{D}]-\frac{1}{2} \Phi_{i} \int_{0}^{R\left(q^{*}\right)} \tilde{p}_{R}^{-1}(\alpha) R^{-1}(\alpha) \mathrm{d} \alpha \\
& =\Phi_{i} E\left[\tilde{\Pi}_{S C}\right]^{*} .
\end{aligned}
$$

Theorem 6 is proved.

\section{Numerical Examples}

For further elucidating above proposed models, we provide numerical examples in this section. Taking a three-echelon supply chain as an example, Let actor 1, 2 and 3 denotes the retailer, the distributor and the manufacturer, respectively. We discuss the impacts of fuzziness of retail price $\tilde{p}$ and demand $\tilde{D}$, and the values of contract parameters on optimal results in the RS contract.

\subsection{Discussion 1}

In this subsection, we discuss the impact of fuzziness of retail price $\tilde{p}$ on the optimal results in the RS contract.

The fuzzy demand estimated by the decision maker's experience is supposed to be nearly 300 , but not less than 200 and not greater than 400 , that is $\tilde{D}=(200,300,400)$. Similarly, the operational cost of the retailer is about $\$ 2$, but not less than 1 and not greater than $\$ 3$, that is $\tilde{c}_{1}=(1,2,3)$. The operational cost of the distributor is about $\$ 3$, but not less than 2 and not greater than $\$ 4$, that is $\tilde{c}_{2}=(2,3,4)$. The operational cost of the distributor is about $\$ 15$, but not less than 13 and not greater than $\$ 17$, that is $\tilde{c}_{3}=(13,15,17)$.

From Theorem 5, we can obtain the optimal wholesale prices

$$
w_{2}{ }^{*}=8.00 \text { and } w_{3}{ }^{*}=9.00 \text {. }
$$

Since the optimal order quantity $q^{*}$ has two cases, then the other optimal policies and expected profit for supply chain actors in the RS contract can be listed in Tables 1 and 2 .

\begin{tabular}{ccccc}
\multicolumn{5}{c}{ Table 1. The RS contract policies when $20<p<40-0.5 \Delta_{2}$} \\
\hline$\tilde{p}$ & $q^{*}$ & $E\left[\tilde{\Pi}_{1}\right]^{*}$ & $E\left[\tilde{\Pi}_{2}\right]^{*}$ & $E\left[\tilde{\Pi}_{3}\right]^{*}$ \\
\hline$(30,30,30)$ & 266.67 & 1166.67 & 700.00 & 466.67 \\
$(29,30,31)$ & 268.16 & 1171.07 & 702.64 & 468.43 \\
$(28,30,32)$ & 269.69 & 1175.65 & 705.39 & 470.26 \\
$(27,30,33)$ & 271.25 & 1180.40 & 708.24 & 472.16 \\
$(26,30,34)$ & 272.84 & 1185.33 & 711.19 & 474.13 \\
$(25,30,35)$ & 274.46 & 1190.44 & 714.26 & 476.18 \\
\hline
\end{tabular}

Table 2. The RS contract policies when $p>40-0.5 \Delta_{2}$

\begin{tabular}{ccccc}
\hline$\tilde{p}$ & $q^{*}$ & $E\left[\tilde{\Pi}_{1}\right]^{*}$ & $E\left[\tilde{\Pi}_{2}\right]^{*}$ & $E\left[\tilde{\Pi}_{3}\right]^{*}$ \\
\hline$(50,50,50)$ & 320.00 & 3900.00 & 2340.00 & 1560.00 \\
$(49,50,51)$ & 320.96 & 3910.86 & 2351.45 & 1567.64 \\
$(48,50,52)$ & 321.90 & 3921.83 & 2362.62 & 1575.08 \\
$(47,50,53)$ & 322.84 & 3932.91 & 2373.53 & 1582.35 \\
$(46,50,54)$ & 323.77 & 3944.11 & 2384.18 & 1589.45 \\
$(45,50,55)$ & 324.70 & 3955.41 & 2394.60 & 1596.40 \\
\hline
\end{tabular}

From Tables 1 and 2, we can get the results as follows

(1) When $20<p<40-0.5 \Delta_{2}, q^{*}$ lies in the left side of the most possible value of parameter $\tilde{D}$, when $p>40-0.5 \Delta_{2}$, the optimal order quantity $q^{*}$ lies in the right side of the most possible value of parameter $\tilde{D}$.

(2)The change of fuzziness of retail price $\tilde{p}$ will not affect wholesale prices $w_{2}{ }^{*}$ and $w_{3}{ }^{*}$. In addition, the optimal wholesale prices $w_{2}{ }^{*}$ and $w_{3}{ }^{*}$ in case 1 showed in Table 1 are the same in case 2 showed in Table 2 . This is because the fuzzy retail price $\tilde{p}$ will not affect optimal wholesale prices, and the wholesale prices are impacted only by the operational costs $\tilde{c}_{1}, \tilde{c}_{2}$ and $\tilde{c}_{3}$.

(3) $q^{*}$ and the expected profits for actors will increase slightly, as the fuzziness of retail price $\tilde{p}$ increases. This is because an increase in fuzziness of retail price results in an increase in order quantity. This results in the 
increase of the fuzzy expected profit for the supply chain members. Therefore, in two cases, actors should seek as high fuzziness of retail price $\tilde{p}$ as possible.

(4) If $\Delta_{1}=\Delta_{2}=0$, then the results in this paper can reduce to the solutions in the symmetric information environment as showed in the second rows in Tables 1 and 2. Comparing these solutions, we can find that $q^{*}$ and expected profits for actors in the asymmetric information environment are higher that those in the symmetric information environment. It indicates that all the supply chain actors can benefit from the asymmetric information in a fuzzy environment.

\subsection{Discussion 2}

In this subsection, we discuss the impact of the fuzziness of parameter $\tilde{D}$ on the RS contract policies. The values of the costs for supply chain actors are considered as before.

From Theorem 5, we can get the optimal wholesale prices in this discussion as $w_{2}{ }^{*}=8.00$ and $w_{3}{ }^{*}=9.00$.

The other optimal solutions derived are shown in Tables 3 and 4.

Table 3. The RS contract policies when $\tilde{p}=(28,30,32)$

\begin{tabular}{ccccc}
\hline$\tilde{D}$ & $q^{*}$ & $E\left[\tilde{\Pi}_{1}\right]^{*}$ & $E\left[\tilde{\Pi}_{2}\right]^{*}$ & $E\left[\tilde{\Pi}_{3}\right]^{*}$ \\
\hline$(200,300,400)$ & 269.69 & 1175.65 & 705.39 & 470.26 \\
$(210,300,390)$ & 272.72 & 1208.08 & 724.85 & 483.23 \\
$(220,300,380)$ & 275.76 & 1240.52 & 744.31 & 496.21 \\
$(230,300,370)$ & 278.79 & 1272.95 & 763.77 & 509.18 \\
$(240,300,360)$ & 281.82 & 1305.39 & 783.23 & 522.15 \\
$(250,300,350)$ & 284.85 & 1337.82 & 802.69 & 535.13 \\
\hline
\end{tabular}

Table 4. The RS contract policies when $\tilde{p}=(48,50,52)$

\begin{tabular}{ccccc}
\hline$\tilde{D}$ & $q^{*}$ & $E\left[\tilde{\Pi}_{1}\right]^{*}$ & $E\left[\tilde{\Pi}_{2}\right]^{*}$ & $E\left[\tilde{\Pi}_{3}\right]^{*}$ \\
\hline$(200,300,400)$ & 321.90 & 3921.83 & 2353.10 & 1568.73 \\
$(210,300,390)$ & 319.71 & 3979.65 & 2387.79 & 1591.86 \\
$(220,300,380)$ & 317.52 & 4037.46 & 2422.48 & 1614.99 \\
$(230,300,370)$ & 315.33 & 4095.28 & 2457.17 & 1638.11 \\
$(240,300,360)$ & 313.14 & 4153.10 & 2491.86 & 1661.24 \\
$(250,300,350)$ & 310.95 & 4210.91 & 2526.55 & 1684.37 \\
\hline
\end{tabular}

(5) $q^{*}$ will rise as the fuzziness of demand $\tilde{D}$ falls when $20<p<40-0.5 \Delta_{2}$. While, $q^{*}$ will drop as the fuzziness of demand $\tilde{D}$ falls when $p>40-0.5 \Delta_{2}$. In two cases, the change of fuzziness of demand $\tilde{D}$ will not affect optimal wholesale prices $w_{2}{ }^{*}$ and $w_{3}{ }^{*}$.
(6) $q^{*}$ and the expected profits for actors will all increase slightly, when the fuzziness of demand $\tilde{D}$ decreases. That is to say, the manufacturer, distributor and retailer all gain more expected profit when the fuzziness of demand is lower. This is intuitive because the lower the fuzziness of demand, the more efficient of the supply chain system. Therefore, actors should seek as low fuzziness of demand $\tilde{D}$ as possible.

\subsection{Discussion 3}

In this subsection, we discuss the impact of parameters $\Phi_{2}$ and $\Phi_{3}$ on the RS contract policies. The values of the costs for supply chain actors are considered as before.

When the fuzzy retail price $\tilde{p}=(28,30,32)$, From Theorem3, we can get the optimal order quantity as

$$
q^{*}=269.69 \text {. }
$$

When the fuzzy retail price $\tilde{p}=(48,50,52)$, From Theorem3, we can get the optimal order quantity as

$$
q^{*}=321.90 \text {. }
$$

The other optimal solutions derived are shown in Tables 5 and 6.

Table 5. The RS contract policies when $\tilde{p}=(28,30,32)$

\begin{tabular}{cccccc}
\hline$\left(\Phi_{2}, \Phi_{3}\right)$ & $w_{2}{ }^{*}$ & $w_{3}^{*}$ & $E\left[\tilde{\Pi}_{1}\right]^{*}$ & $E\left[\tilde{\Pi}_{2}\right]^{*}$ & $E\left[\tilde{\Pi}_{3}\right]^{*}$ \\
\hline$(0.30,0.20)$ & 8.00 & 9.00 & 1175.65 & 705.39 & 470.26 \\
$(0.30,0.25)$ & 9.00 & 9.00 & 1058.08 & 705.39 & 587.82 \\
$(0.30,0.30)$ & 10.00 & 9.00 & 940.52 & 705.39 & 705.39 \\
$(0.35,0.20)$ & 9.00 & 8.00 & 1058.08 & 822.95 & 470.26 \\
$(0.40,0.20)$ & 10.00 & 7.00 & 940.52 & 940.52 & 470.26 \\
$(0.45,0.20)$ & 11.00 & 6.00 & 822.95 & 1058.08 & 470.26 \\
\hline
\end{tabular}

Table 6. The RS contract policies when $\tilde{p}=(48,50,52)$

\begin{tabular}{cccccc}
\hline$\left(\Phi_{2}, \Phi_{3}\right)$ & $w_{2}{ }^{*}$ & $w_{3}{ }^{*}$ & $E\left[\tilde{\Pi}_{1}\right]^{*}$ & $E\left[\tilde{\Pi}_{2}\right]^{*}$ & $E\left[\tilde{\Pi}_{3}\right]^{*}$ \\
\hline$(0.30,0.20)$ & 8.00 & 9.00 & 3921.83 & 2353.10 & 1568.73 \\
$(0.30,0.25)$ & 9.00 & 9.00 & 3529.65 & 2353.10 & 1960.91 \\
$(0.30,0.30)$ & 10.00 & 9.00 & 3137.46 & 2353.10 & 2353.10 \\
$(0.35,0.20)$ & 9.00 & 8.00 & 3529.65 & 2745.28 & 1568.73 \\
$(0.40,0.20)$ & 10.00 & 7.00 & 3137.46 & 3137.46 & 1568.73 \\
$(0.45,0.20)$ & 11.00 & 6.00 & 2745.28 & 3529.65 & 1568.73 \\
\hline
\end{tabular}

(7)The change of the parameters $\Phi_{2}$ and $\Phi_{3}$ will not affect the optimal order quantity $q^{*}$. With the increasing of $\Phi_{2}, w_{2}{ }^{*}$ will increase, but $w_{3}{ }^{*}$ will decrease, when the parameter $\Phi_{3}$ is fixed. With the increasing of $\Phi_{3}$, 
$w_{2}{ }^{*}$ will increase, and $w_{3}{ }^{*}$ will not vary, when the parameter $\Phi_{2}$ is fixed.

(8)The optimal expected profit for actor 2 increases as the parameter $\Phi_{2}$ increase. As the parameter $\Phi_{3}$ drops, the expected profit for actor 3 falls. The expected profit for actor 1 decreases when the value of sum of $\Phi_{2}$ and $\Phi_{3}$ increases. In addition, if $\Phi_{2}=\Phi_{3}$, then the expected profit for actor 2 is the same as that for actor 3.Therefore, the RS contract is an effective tool in coordinating the supply chain, as we can set the reasonable values of parameters $\Phi_{2}$ and $\Phi_{3}$ by negotiating between supply chain actors without sacrificing the expected maximum profit for supply chain system.

\section{Conclusions}

This paper deals with the coordination strategy in a multi-stage supply chain, where actors adopt the RS contract to coordinate the supply chain. For examining the performance of supply chain models with fuzzy demand and asymmetric information, we use the fuzzy set theory to solve these problems. We find that the optimal wholesale prices do not vary as the fuzziness of the retail price and demand decrease, the supply chain members should seek as low fuzziness of demand as possible, and all the supply chain actors can benefit from the asymmetric information in a fuzzy environment.

Based on the discussions above, the following findings can be obtained. Firstly, the optimal order quantity and the expected profits for actors in the asymmetric information environment are higher that those in the symmetric information environment. Secondly, the optimal order quantity and the expected profits for actors will all increase slightly, when the fuzziness of market demand decreases. Thirdly, the RS contract is an effective tool in coordinating the multiple echelon supply chain, as we can set the reasonable values of parameters in the contract by negotiating between supply chain actors without sacrificing the expected maximum profit for supply chain system.

One limitation of this article is that we only consider one actor in each echelon supply chain. Another limitation is that supply chain actors are all risk neutral. It is interesting to extend our modes to conditions with multiple competing supply chain actors. Still, we will discuss the problem how to design the contract policies when the actors are risk averse in a fuzzy environment.

\section{Acknowledgements}

This work was supported by the Shandong Provincial Natural Science Foundation, China (No. ZR2015GQ 001), and the Project of Shandong Provincial Higher Educational Humanity and Social Science Research Program (No. J15WB04).

\section{References}

1. G. P. Cachon and M.A. Lariviere, Supply chain coordination with revenue-sharing contracts: strengths and limitations, Manage Sci. 51 (1) (2005) 30-44.

2. J. Hou, A.Z. Zeng and L. Zhao, Achieving better coordination through revenue sharing and bargaining in a two-stage supply chain, Comput Ind Eng. 57 (1) (2009) 383-394.

3. I. Giannoccaro and P. Pontrandolfo, Negotiation of the revenue sharing contract: An agent-based systems approach, Int J Prod Econ. 122(2) (2009) 558-566.

4. J.M. Chen, H.L. Cheng and M.C. Chien, On channel coordination through revenue-sharing contracts with price and shelf-space dependent demand, Appl Math Model. 35 (10) (2011) 4886-4901.

5. J.B. Sheu, Marketing-driven channel coordination with revenue-sharing contracts under price promotion to endcustomers, Eur J Oper Res. 214(2) (2011) 246-255.

6. M. Kunter, Coordination via cost and revenue sharing in manufacturer-retailer channels, Eur J Oper Res. 216(2) (2012) 477-486.

7. J. M. Chen and H. L. Cheng, Effect of the price-dependent revenue-sharing mechanism in a decentralized supply chain, Cent Eur J Oper Res. 20(2) (2012) 299-317.

8. G.P. Sarathi, S.P. Sarmah and M. Jenamani, An integrated revenue sharing and quantity discounts contract for coordinating a supply chain dealing with short life-cycle products, Appl Math Model. 38(15-16) (2014) 4120-4136.

9. K. Govindan and M.N. Popiuc, Reverse supply chain coordination by revenue sharing contract: A case for the personal computers industry, Eur J Oper Res. 233(2) (2014) 326-336.

10. S. Panda, Coordination of a socially responsible supply chain using revenue sharing contract, Transport Res ELog. 67 (2014) 92-104.

11. J. M. Chen and H. L. Cheng, Effect of the price-dependent revenue-sharing mechanism in a decentralized supply chain, Cent Eur J Oper Res. 20 (2) (2012) 299-317.

12. C.T. Linh and Y. Hong, Channel coordination through a revenue sharing contract in a two-period newsboy problem, Eur J Oper Res. 198(3) (2009) 833-829.

13. O.D. Palsule-Desai, Supply chain coordination using revenue-dependent revenue sharing contracts, Omega. 41(4) (2013) 780-796. 
14. Z. Yao, S.C.H. Leung and K.K. Lai, Manufacturer's revenue-sharing contract and retail competition, Eur $J$ Oper Res. 186(2) (2008) 637-651.

15. K. Pan, K.K. Lai, S.C.H. Leung and D. Xiao, Revenuesharing versus wholesale price mechanisms under different channel power structures, Eur J Oper Res. 203(2) (2010) 532-538.

16. F. El. Ouardighi and B. Kim, Supply quality management with wholesale price and revenue-sharing contracts under horizontal competition, Eur J Oper Res. 206(2) (2010) 329-340.

17. H. Krishnan and R.A. Winter, On the role of revenuesharing contracts in supply chains, Oper Res Lett. 39(1) (2011) 28-31.

18. W.G. Zhang, F. Fu, H.Li and W. Xu, Coordination of supply chain with a revenue-sharing contract under demand disruptions when retailers compete, Int J Prod Econ. 138(1) (2012) 68-75.

19. T. Chakraborty, S.S Chauhan and N. Vidyarthi, Coordination and competition in a common retailer channel: Wholesale price versus revenue-sharing mechanisms, Int J Prod Econ. 166(2015)103-118.

20. J. Zhang, G. Liu, Q. Zhang and Z. Bai, Coordinating a supply chain for deteriorating items with a revenue sharing and cooperative investment contract, Omega. 56(3) (2015)37-49.

21. H.V. Arani, M. Rabbani and H. Rafiei, A revenue-sharing option contract toward coordination of supply chains, Int $J$ Prod Econ. 178 (2016)42-56.

22. I. Giannoccaro and P. Pontrandolfo, Supply chain coordination by revenue sharing contracts, Int J Prod Econ. 89(2) (2004) 131-139.

23. B. Van Der Rhee, J.A.A. Van Der Veen, V. Venugopal and V.R. Nalla, A new revenue sharing mechanism for coordinating multi-echelon supply chains, Oper Res Lett. 38(4) (2010), 296-301.

24. B. Van Der Rhee, G. Schmidt, J.A.A. Van Der Veen and V. Venugopal, Revenue-sharing contracts across an extended supply chain, Bus Horizons. 57(4) (2014), 473482

25. L. Jiang, Y. Wang, X. Yan and W. Dai, Coordinating a three-stage supply chain with competing manufacturers, Cent Eur J Oper Res. 22(1) (2014) 53-72.

26. X. Feng, I. Moon and K. Ryu, Revenue-sharing contracts in an N-stage supply chain with reliability considerations, Int J Prod Econ. 147(1) (2014) 20-29.

27. J. Wang, R. Zhao and W. Tang, Supply chain coordination by revenue-sharing contract with fuzzy demand, $J$ Intell Fuzzy Syst. 19(6) (2008) 409-420.

28. S. Sang, Supply chain contracts with multiple retailers in a fuzzy demand environment, Math Probl Eng. 2013 (2013) $1-12$.

29. C. Zhou, R. Zhao and W. Tang, Two-echelon supply chain games in a fuzzy environment, Comput Ind Eng. 55(2) (2008), 390-405.
30. S. Sang, Optimal models in price competition supply chain under a fuzzy decision environment, $J$ Intell Fuzzy Syst. 27(1) (2014) 257-271.

31. J.F. Dang and I.H. Hong, The Cournot game under a fuzzy decision environment, Comput Math Appl. 59(9) (2010) 3099-3109.

32. J.F. Dang, I.H. Hong and J.M. Lin, The Cournot production game with multiple firms under an ambiguous decision environment, Inf Sci. 266(5) (2014) 186-198.

33. J. Zhao, W. Tang and J. Wei, Pricing decision for substitutable products with retail competition in a fuzzy environment, Int J Prod Econ. 135(1) (2012) 144-153.

34. J. Zhao, W. Liu and J. Wei, Competition under manufacturer service and price in fuzzy environments, Knowl-Based Syst. 50(3) (2013) 121-133.

35. J. Zhao and L. Wang, Pricing and retail service decisions in fuzzy uncertainty environments, Appl Math Comput. 250 (2015) 580-592.

36. J. Wei and J. Zhao, Pricing decisions with retail competition in a fuzzy closed-loop supply chain, Expert Syst Appl. 38(9) (2011) 11209-11216.

37. J. Wei and J. Zhao, Reverse channel decisions for a fuzzy closed-loop supply chain, Appl Math Model. 37(3) (2013) $1502-1513$.

38. A.A. Khamseh, F. Soleimani and B. Naderi, Pricing decisions for complementary products with firm's different market powers in fuzzy environments, $J$ Intell Fuzzy Syst. 27 (5) (2014) 2327-2340.

39. S. Sang, Price competition of manufacturers in supply chain under a fuzzy decision environment, Fuzzy Optim Decis Making. 14(3) (2015)335-363.

40. R. Xu and X. Zhai, Optimal models for single-period supply chain problems with fuzzy demand, Inf Sci. 178(17) (2008) 3374-3381.

41. R. Xu, and X. Zhai, Analysis of supply chain coordination under fuzzy demand in a two-stage supply chain, Appl Math Model. 34(1) (2010) 129-139.

42. Y. Yu and T. Jin, The return policy model with fuzzy demands and asymmetric information, Appl Soft Comput. 11(2) (2011) 1669-1678.

43. Y. Yu, J. Zhu and C. Wang, A newsvendor model with fuzzy price-dependent demand, Appl Math Model. 37(5) (2013) 2644-2661.

44. S.Y. Chang and T.Y. Yeh, A two-echelon supply chain of a returnable product with fuzzy demand, Appl Math Model. 37(6) (2013) 4305-4315.

45. B. Zhang, S. Lu, D. Zhang and K. Wen, Supply chain coordination based on a buyback contract under fuzzy random variable demand, Fuzzy Sets Syst. 255 (2014) 116.

46. B. Liu and Y. Liu, Expected value of fuzzy variable and fuzzy expected value models, IEEE T Fuzzy Syst. 10(4) (2002) 445-450. 